\title{
Correction to: Dealing with Uncertainty: From Rough Sets to Interactive Rough-Granular Computing
}

Andrzej Jankowski, Andrzej Skowron and Roman Swiniarski

\section{Correction to:}

Chapter "Dealing with Uncertainty: From Rough Sets to Interactive Rough-Granular Computing" in: M.K. Chakraborty et al. (eds.), Facets of Uncertainties and Applications, Springer Proceedings in Mathematics \& Statistics 125, https://doi.org/10.1007/978-81-322-2301-6_2

In the original version of the book, the grant numbers approved by Polish National Science Centre (NCN), mentioned in the acknowledgement section of Chapter 2 has been revised from "DEC-2011/01/D /ST6/ 06981, DEC-2012/05/B/ST6/03215, and DEC-2013/09/B/ST6/01568" to "DEC-2011/01/D /ST6/ 06981 and DEC-2012/ 05/B/ST6/03215", which is a belated correction. The correction has been updated in the chapter. 